\title{
In Defence of Virtue: The Legitimacy of Agent-Based Argument Appraisal
}

\author{
ANDREW ABERDEIN \\ School of Arts and Communication \\ Florida Institute of Technology \\ 150 West University Boulevard, Melbourne \\ Florida 32901-6975, U.S.A. \\ aberdein@fit.edu
}

\begin{abstract}
Several authors have recently begun to apply virtue theory to argumentation. Critics of this programme have suggested that no such theory can avoid committing an ad hominem fallacy. This criticism is shown to trade unsuccessfully on an ambiguity in the definition of ad hominem. The ambiguity is resolved and a virtue-theoretic account of ad hominem reasoning is defended.
\end{abstract}

Résumé: Plusieurs auteurs ont récemment commencé à appliquer la théorie des vertus à l'argumentation. Les critiques de ce programme ont suggéré qu'une telle théorie ne peut éviter de commettre un sophisme ad hominem. On montre que cette critique repose sur une ambiguïté dans la définition de «ad hominem». On résout l'ambiguïté et on défend une explication du raisonnement ad hominem qui est fondée la théorie de la vertu.

Keywords: ad hominem, argumentational vice, argumentational virtue, fallacy, virtue argumentation

\section{Introduction}

Virtue theory originates in ethics, and in particular the work of Aristotle. In recent years, it has come to be applied to other fields of philosophy, most conspicuously epistemology. There are two main constituencies among virtue epistemologists, distinguished by their different characterizations of virtue. Reliabilists understand virtues to be reliable faculties, such as sight or logical inference. For responsibilists virtues are acquired character traits, such as open-mindedness or intellectual humility. Both sorts of virtue epistemologist agree that virtues must be reliable, but they disagree whether the agent has any responsibility for their acquisition or maintenance (Battaly, p. 365). Some applications of virtue theory to argumentation are simply continuations of virtue epistemology: the role of the virtues in good argument is seen as promoting the acquisition of knowledge (for example, Johnson; Battaly). It is also possible to characterize argumentational virtues as distinct from epistemic virtues (for example, 
Cohen, 2009; Aberdein; Correia: see Section 4 below for further discussion).

In a recent article, Tracy Bowell and Justine Kingsbury subject this emerging programme to a detailed critique. They accept that virtue talk can be a useful means of articulating important features of argumentation, but conclude that "virtue argumentation theory does not offer a plausible alternative to a more standard agent-neutral account of good argument" (Bowell and Kingsbury, p. 23). The careful attention that they have paid to virtue argumentation theory is very welcome, but I shall argue that the programme emerges from their criticisms unscathed.

Bowell and Kingsbury identify argument with rational persuasion, thereby situating themselves within an epistemological approach to argumentation (as defined in Lumer, p. 190). They concede that not all argumentation theorists would accept this characterization, but observe correctly that it is "widespread" (Bowell and Kingsbury, p. 23, note 1). Nonetheless, this concession exempts from Bowell and Kingsbury's critique any application of virtue theory to rhetorical approaches, such as advocated by Perelman and Olbrechts-Tyteca or Hamblin, or consensus approaches, such as van Eemeren and Grootendorst's pragma-dialectics and Habermas's discourse theory (again, see Lumer, pp. 189 f., for definitions). Both rhetorical and consensus approaches seem promising ground for virtue theory, but I shall presently restrict my attention to the epistemological approach.

Bowell and Kingsbury state that a "good argument is an argument that provides, via its premises, sufficient justification for believing its conclusion to be true or highly probable, or for accepting that the course of action it advises is one that certainly or highly probably should be taken" (Bowell and Kingsbury, p. 23). They contend that "this is not an account of good argument that a virtue argumentation theorist would accept" (ibid.). But the virtue argumentation theorist can accept this definition, provided that "sufficient justification" is understood in terms of the virtues of the arguer (and, perhaps, those of the respondent). The virtue theorist may wish to reject Bowell and Kingsbury's account of argument for other reasons, ${ }^{1}$ but would only be com-

\footnotetext{
${ }^{1}$ In particular, Bowell and Kingsbury's account emphasizes a conception of argument evaluation as the evaluation of a text or product rather than of an activity. This approach might be accused of begging the question against the (rhetorical or dialectical) accounts of argument evaluation most congenial to a virtue-theoretic approach. However, in what follows I will also focus on the evaluation of arguments as objects, rather than risk begging the question in
}

(C) Andrew Aberdein. Informal Logic, Vol. 34, No. 1 (2014), pp. 77-93. 
pelled to do so in order to endorse virtue argumentation theory without endorsing virtue epistemology. This seems a perverse aspiration, especially if one's approach to argumentation is expressly epistemological. In sum, once the epistemological approach is coupled to virtue epistemology, virtue argumentation theory is the natural result.

However, the central focus of Bowell and Kingsbury's critique concerns the ad hominem fallacy. This fallacy has attracted much attention from virtue theorists (for example Johnson; Aberdein; Battaly). Since the standard account of ad hominem classifies as fallacious all agent-based appraisal of argument, and thereby any meaningful virtue theory of argumentation, defenders of such theories require a more permissive account. Bowell and Kingsbury argue that no such account is available. In Section 2 I will show that this criticism of virtue argumentation unsuccessfully trades on an ambiguity in the definition of ad hominem. Section 3 provides examples of legitimate ad hominem reasoning and Section 4 provides a positive virtue-theoretic account of ad hominem reasoning by developing the idea that ad hominem may be legitimate "precisely when it is used to draw attention to argumentational vice" (Aberdein, p. 171).

\section{Virtue theory of argumentation as ad hominem}

The most conspicuous obstacle to a virtue-theoretic approach to argument appraisal lies in the standard account of the ad hominem fallacy, on which assessing the arguer rather than (or as well as) the argument is stigmatized as fallacious: "Any shift in the direction of an agent-based approach may itself appear to commit some kind of illegitimate ad hominem move" (Bowell and Kingsbury, p. 25). Luckily for the virtue theorist, the standard account has been widely contested by authors who defend the legitimacy of at least some ad hominem arguments. However, Bowell and Kingsbury argue that the existence of legitimate ad hominem arguments does not help the virtue theorist, since none of them are the right sort of argument: "Legitimate ad hominem arguments provide reasons to doubt the truth of a claim on the basis of facts about the person making it. It is commonly supposed that it is never reasonable to reject an argument on the basis of such facts, however" (Bowell and Kings-

the opposite direction. I am grateful to an anonymous referee for stressing this point.

(C) Andrew Aberdein. Informal Logic, Vol. 34, No. 1 (2014), pp. 77-93. 
bury, p. 26). That is to say, for Bowell and Kingsbury, an ad hominem argument may legitimately rebut a respondent's argument, but may not undercut it; ${ }^{2}$ since virtue-theoretic argument appraisal requires legitimate ad hominem undercutting, the virtue argumentation programme is illegitimate. To resolve this dispute, we must clarify the underlying ambiguity in the discussion of ad hominem.

Commentators on the ad hominem have long recognized that the term has been used equivocally to refer to several different things (see Hitchcock, for further details). The following list is neither exhaustive nor exclusive: ${ }^{3}$

\section{ad hominem $\mathbf{C}$ : Arguing from the respondent's commitments.}

ad hominems: Arguing that the respondent is disqualified from speaking.

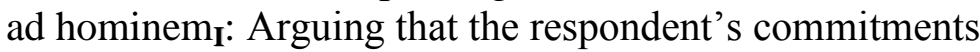
are inconsistent.

ad hominem $\mathbf{R}_{\mathbf{R}}$ : Arguing that the respondent's character rebuts his argument.

ad hominem $\mathrm{U}_{\mathbf{U}}$ : Arguing that the respondent's character undercuts his argument.

Ad hominem ${ }_{C}$ is the sense in which the term was famously used by John Locke: "to press a man with consequences drawn from his own principles or concessions" (Locke, p. 524). ${ }^{4}$ Locke never suggests that ad hominem $\mathrm{C}_{\mathbf{C}}$ is a fallacy. Subsequent authors generally follow suit, except where they have confused ad hominem $_{\mathbf{C}}$ with one of the other varieties. ${ }^{5} \mathrm{Ad}$ hominem $\mathbf{S}$ corre-

\footnotetext{
${ }^{2}$ For a detailed account of the contrast between rebutting and undercutting, see (Pollock, p. 4).

${ }^{3}$ Similar lists may be found in various places, such as (Macagno). There is no precise consensus on how best to subdivide ad hominem, so although my classification is intended not to conflict with Macagno's, I do not claim that the subvarieties on our lists coincide exactly. In particular, Macagno omits what I have termed ad hominem . $_{\text {. }}$.

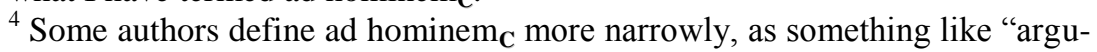
ing from the respondent's commitments to a conclusion not accepted by the respondent". If the respondent expressly rejects the conclusion this would be ad hominem $\mathbf{I}$ as well as ad hominem $\mathbf{C}$.

${ }^{5}$ One exception may be Gary Jason: "If I try to convince you of $\mathrm{C}$ by citing $\mathrm{P}$ where you believe P, but I don't, I am being illogical. I am persuading you, not by sound argument, but by what I believe to be unsound argument" (Jason, p. 185). This seems a confusion. It would be illogical for me to believe $\mathrm{C}$ because you believe P. But there is no illogicality in exploring the consequences of endorsing a position I do not hold - conditional proof, for example, would otherwise be illogical. So, if I believe $\mathrm{C}$ on the basis of independ-
}

(C) Andrew Aberdein. Informal Logic, Vol. 34, No. 1 (2014), pp. 77-93. 
sponds to what many textbooks refer to as 'poisoning the well', after Cardinal Newman's memorable characterization of a move used against him by Charles Kingsley (Copi et al., p. 56). Many contemporary treatments of ad hominem identify ad hominems as a separate fallacy (e.g., Walton, 2006), but there are exceptions, notably Frans van Eemeren and Rob Grootendorst, for whom all varieties of ad hominem "amount to a party claiming that the other party has no right to speak" (van Eemeren and Grootendorst, p. 225). Although van Eemeren and Grootendorst treat ad hominem as inherently fallacious, some other authors who take ad hominem $\mathbf{S}$ as characteristic argue that it is sometimes legitimate (for example, Powers). Ad hominem $\mathbf{I}$ occurs in the textbook tradition as 'tu quoque', in which the arguer points out a pragmatic inconsistency between the respondent's words and deeds. Some contemporary treatments argue that this is the central form of ad hominem (for example, Walton, 1987, p. 329). The textbooks generally assert that ad hominem Is invariably fallacious. However, provided that it is understood as undercutting, not rebutting, it would appear to be reasonable in most cases (Hitchcock, p. 616). More generally, the distinction between undercutting and rebutting an argument separates ad hominem $_{\mathbf{R}}$ from ad hominem $\mathbf{U}$ : an ad hominem $\mathbf{R}$ retort would state that the respondent's conclusion was false; an ad hominem $_{\mathbf{U}}$ retort would state that the respondent has not shown that that conclusion follows from the premisses. This distinction is central to the defence of a virtue theory of argumentation.

In (Aberdein, pp. $170 \mathrm{f}$.) I was concerned to head off the following argument:

1. All virtue-based argument appraisal is agent-oriented.

2. All agent-oriented argument appraisal is ad hominem.

3. All ad hominem reasoning is fallacious.

$\therefore$ All virtue-based argument appraisal is fallacious.

I argued that premiss (3) is false, citing several argumentation theorists who have defended the ad hominem as not necessarily fallacious. Significantly, the ad hominem in premiss (2) is ad hominem $_{\mathbf{U}}$, since it is addressed to the appraisal of arguments. Thus the premiss I need to reject is

$3^{\prime}$. All ad hominem $\mathbf{U}$ reasoning is fallacious.

ent sound arguments which for some reason you won't accept, I may legitimately use ad hominem $\mathbf{C}_{\mathbf{C}}$ to persuade you that you ought to share my belief, irrespective of whether I believe P.

(C) Andrew Aberdein. Informal Logic, Vol. 34, No. 1 (2014), pp. 77-93. 
Examples of legitimate ad hominem of any of the other three varieties would not demonstrate this (unless they happen to be ad hominem $\mathbf{U}$ too). Thus we may paraphrase Bowell and Kingsbury as countering that I have not shown $\left(3^{\prime}\right)$ to be false, since all known counterexamples to (3) exemplify other varieties of ad hominem, primarily ad hominem $\mathbf{R}$. Is that so?

There are some accounts of ad hominem on which ad hominem $_{\mathbf{R}}$ is central. For example, Jason defines ad hominem as follows:

The advocates of (proposition, claim, proposal) $\mathrm{C}$ have traits $\mathrm{x}, \mathrm{y}, \mathrm{z}, \ldots$

$\mathrm{x}, \mathrm{y}, \mathrm{z}, \ldots$ are all bad.

$\therefore \mathrm{C}$ is (probably) false. (Jason, p. 182)

However, Jason also holds ad hominem to be invariably fallacious. On the other hand, Merilee Salmon has a highly idiosyncratic characterization of ad hominem as sometimes legitimate and intrinsically ad hominem $\mathbf{R}_{\mathbf{R}}$ :

Most of what individual $a$ says about a particular subject matter $S$ is false.

$a$ says $p$ about $S$.

Therefore, $p$ is false. (Salmon, p. 121)

On this account, ad hominem $\mathbf{R}_{\mathbf{R}}$ is legitimate when this statistical syllogism is inductively strong.

Nonetheless, there are also many defenders of legitimate ad hominem $\mathbf{U}$. For example, Alan Brinton defines "normal, nonfallacious" ad hominem as "consist[ing] in bringing alleged facts about Jones to bear in an attempt to influence hearers' attitudes toward Jones's advocacy-of- $P$. That is to say, the conclusion of logically healthy ad hominem will be about Jones's advocacy of $P$; it will not be about $P$ itself" (Brinton, p. 214). But he observes that "it is possible, though not typical, that a deviant adhominist extends the attack to $P$ itself"- - that is, switches to ad hominem $\mathbf{R}_{\mathbf{R}}$ (Brinton, p. 217). Brinton continues, "It is when adhominizing goes wrong in this way, in terms of a clearly identifiable structural failure, that it makes most sense to speak of a specifically ad hominem fallacy" (ibid.). Harvey Siegel and John Biro provide a similar analysis to Brinton's. They argue that in ad hominem "we attempt to persuade ourselves or our audience that some property of the advocate of a certain claim justifies us in rejecting that advocacy as providing reason for the claim", that is, ad hominem $\mathbf{U}$ (Siegel and Biro, p. 287). They add that "It 
is, of course, a mistake to think that doing so is, in and of itself, to provide an argument for the denial of the claim", that is, ad hominem $_{\mathbf{R}}$ (ibid.). Heather Battaly concurs with this analysis. She "identifies two sorts of ad hominem arguments that are illegitimate, including ad hominems that ask us to dismiss the speaker's arguments [ad hominem $\mathbf{S}$ ] or conclude that her claims are false [ad hominem $\mathbf{R}$ ]. In contrast, legitimate ad hominems merely conclude that we should not believe what the speaker says solely on her say-so [ad hominemu]" (Battaly, p. 367). So all three of these analyses directly contradict Bowell and Kingsbury, since each defends ad hominem $\mathbf{U}$ by denying the legitimacy of ad hominem $\mathbf{R}$.

In a somewhat different approach, John Woods defends the legitimacy of both ad hominem $\mathbf{R}$ and ad hominem $\mathbf{U}$. He schematizes the overall ad hominem strategy as follows:

1. Sarah makes her ad hominem retort.

2. She concludes from this that the adequacy of her opponent's case is called into doubt.

3. She concludes from this that there is reason to think that her interlocutor's position is false. (Woods, p. 124)

Woods observes that "Some people are of the view that an argumentum ad hominem is constituted by all three components, the retort of (1) and the inferences of (2) and (3).... Others are of the view that the ad hominem has a slighter constitution, one that begins with (1) and ends with (2)" (ibid.). On the former view, all ad hominem arguments are ad hominem ${ }_{\mathbf{R}}$; on the latter they are all ad hominem $\mathbf{U}$. However, if Woods's analysis is correct, ad hominem $\mathbf{R}_{\mathbf{R}}$ arguments only rebut claims by first undercutting the arguments supporting those claims. This is just as unhelpful for Bowell and Kingsbury as the analyses discussed above, since it means that if there are legitimate ad hominem $\mathbf{R}_{\mathbf{R}}$ arguments, there must be legitimate ad hominem $\mathbf{U}$ arguments too.

We have seen that, contrary to Bowell and Kingsbury, it is not "commonly supposed" that ad hominem $\mathbf{U}$ arguments are always fallacious (Bowell and Kingsbury, p. 26). However, we have not yet seen any positive examples of legitimate ad hominem $_{\mathbf{U}}$ arguments. I will address this in the next section. 


\section{Legitimate ad hominem undercutting}

At first blush, deductive logic may seem the least promising territory in which to look for legitimate ad hominem undercutters. Defenders and critics of legitimate ad hominem agree that an "argument either is valid or it is not, and this is determined by seeing whether it conforms to the relevant rules, not by looking at the motives of the person advancing the argument. If Hitler advanced an argument using modus ponens, it would be valid" (Hinman, p. 339). As Bowell and Kingsbury put it, "facts about the arguer cannot undermine the validity of a deductive argument, or make an invalid argument valid" (Bowell and Kingsbury, p. 27). This is entirely correct, provided that 'argument' is understood to mean 'argument form'. For example, conjunction introduction is a valid form in most systems of formal logic; if someone utters an argument having that form, then their argument is valid in any of those systems, irrespective of any facts about them. But people don't utter logical forms, they utter natural language sentences. If we wish to appraise an argument formally, we must first ascribe a form to it. Satisfactory completion of that task can easily require us to know facts about the arguer. Consider this example:

Here it is hot.

Here it is humid.

Therefore here it is hot and humid. (Sorensen, p. 321)

This argument would have the valid form of conjunction introduction if both premisses are uttered in the same place; if not, the premisses are equivocal and the appropriate form would be invalid. But the physical location of the arguer when the premisses are uttered is clearly a fact about the arguer. Thus this is a case where facts about the arguer determine whether an argument has a valid or invalid form, or more casually, whether it is valid or invalid.

It might reasonably be objected that physical location is not a fact about the arguer's character, and therefore that this could not be the object of an ad hominem critique, legitimate or illegitimate. However, there are many sources of equivocation in natural language argumentation. To take a recent example, consider the following tweet: "Two thirds of the Cabinet-18 out of 29 ministers - are millionaires. Tomorrow, unlike you, they'll get a $£ 42,000$ tax cut” (@BolsoverBeast). On a charitable interpretation, this could be analysed by the following valid syllogism (with an enthymematic major premiss): 
[All millionaires will get a $£ 42,000$ tax cut tomorrow.] 18 Cabinet ministers are millionaires.

So, 18 Cabinet ministers will get a $£ 42,000$ tax cut tomorrow.

However, the word 'millionaire' is used equivocally. In the minor premiss it is used in its (British) dictionary sense to refer to someone with a net worth of at least $£ 1,000,000$; in the (implicit) major premiss and the conclusion it is used in a non-standard sense recently employed by the British Labour Party to refer to someone with an annual income of at least $£ 1,000,000$. The conclusion is unwarranted (and presumably false).

A common practice in such cases is to employ a principle of charity: to err on the side of validity whenever in doubt over how to formalize an argument. This has the powerful rhetorical advantage that if the argument still ends up invalid, then the case against it is all the more compelling for being so obviously fairly made. But what should one do when a charitably formalized argument is valid? In judging whether or not a subtle equivocation such as this is present in a natural language argument, the character of the arguer may well be a relevant factor. In this example, once we pay attention to the source of this argument, we may wonder if a charitable interpretation is warranted. The tweet is attacking the tax policies of the British government, but the Twitter account uses versions of the name and nickname of a veteran left-winger in the opposition Labour Party. ${ }^{6}$ When we know this, and that the Labour Party has taken to using 'millionaire' idiosyncratically, it is easy to spot that the arguer is equivocating. In pointing this out we are asserting that the arguer is failing to act as a virtuous arguer would act, that is we are making an ad hominem $\mathbf{U}_{\mathbf{U}}$ attack on the arguer, but a wholly legitimate one.

Similar considerations apply to the appraisal of inductive arguments, such as this argument discussed by Bowell and Kingsbury: "someone tries to convince me that Tom is not fluent in German, on the grounds that Tom is a New Zealander and only $2 \%$ of New Zealanders are fluent in German" (Bowell and Kingsbury, p. 27). This plausible argument would be undermined were we to learn, for example, that Tom is the New Zealand ambassador to Germany. Hence it is relevant to its apprais-

\footnotetext{
${ }^{6}$ Dennis Skinner, Member of Parliament for Bolsover since 1970, has long been nicknamed 'The Beast of Bolsover'. However, the @BolsoverBeast account is presumably unauthorized, since it uses the name 'Denis Skinner', misspelling the MP's forename.
}

(C) Andrew Aberdein. Informal Logic, Vol. 34, No. 1 (2014), pp. 77-93. 
al whether or not the arguer is "the sort of person that would delight in tricking me into thinking that the New Zealand ambassador to Germany doesn't speak German" (ibid.). Bowell and Kingsbury admit that this is agent-based appraisal, but they conclude that it is not appraisal of the argument, but of an unstated enthymematic premiss, such as "There is nothing unusual about Tom that bears on the likelihood of his speaking German" (Bowell and Kingsbury, p. 29). However, the reconstruction and appraisal of unstated premisses is not the same task as appraising premisses supplied by the arguer; rather it is part of the task of appraising the argument. Hence, despite Bowell and Kingsbury's analysis, this is a further example of legitimate ad hominem $_{\mathbf{U}}$.

Bowell and Kingsbury also discuss an example of mathematical reasoning, asking whether "there might be areas in which I defer to experts about matters of logic" (Bowell and Kingsbury, p. 28). They consider someone who, when presented with the Monty Hall problem, "is informed by reliable experts that the argument that the contestant should swap is absolutely watertight" (Bowell and Kingsbury, p. 29) and accepts the argument on that basis although she was unable to follow it. They rightly point out that she is primarily relying on an argument from authority for the conclusion that the contestant should swap. However, that seems to be a weakness of the specific example, not of the general principle of agent-based appraisal of complex argument. Some recent empirical research has shown that experts in mathematics treat some arguments as more persuasive if they are attributed to respected mathematicians (Inglis and Mejía-Ramos). This research applies to arguments, not just their conclusions: the participants in the study were explicitly directed "to determine the extent to which the given argument allows them to gain conviction in the (probable) truth or falsity of the argument's conclusion" (Inglis and Mejía-Ramos, p. 39, emphasis in original). This could have been quite independent of the participants' overall confidence in each conclusion, since, as expert mathematicians, they may well have known of a better argument or been able to devise one for themselves.

Of course, the examples in this study concern arguments which were evaluated as more persuasive when their source was known, so although they are cases of agent-based appraisal, they are not strictly speaking ad hominem. However, mathematicians also engage in negative agent-based appraisal. For example, consider Scott Aaronson's "Ten signs a claimed mathematical breakthrough is wrong," a list of heuristics a mathematician may use to determine whether "a complicated solution to a famous

(c) Andrew Aberdein. Informal Logic, Vol. 34, No. 1 (2014), pp. 77-93. 
decades-old math problem ... is worth reading" (Aaronson). Many of the heuristics appeal to the author's "failure to perform intellectually virtuous acts" (Battaly, p. 367). For example, "The authors themselves switch to weasel words by the end", "The paper doesn't build on ... any previous work" or "The paper wastes lots of space on standard material" (Aaronson). As Aaronson notes, these are only heuristics: "If a paper fails one or more tests ... that doesn't necessarily mean it's wrong" (Aaronson). Nonetheless, they reflect the legitimate practice of many working mathematicians. And each of them represents grounds for concluding that the argument contained within the paper may not hold water on the basis of the authors' conduct, and not on the details of their argument. Hence they comprise legitimate ad hominem $\mathbf{U}$ argumentation.

A further example of reasoning where the character of the arguer may be relevant to its evaluation is inference to the best explanation. In defending the legitimacy of (some) ad hominem argumentation aimed at intelligent design (ID) theorists, Christopher Pynes observes that "ID arguments and claims, as well as Darwinian/evolutionary arguments and claims about the origins of species and other biologically related issues, are traditionally presented as inferences to the best explanations.... So validity of the formal, deductive kind is irrelevant" (Pynes, pp. 292 f.). ID theorists profess to have discovered "irreducible complexities" which evolutionary theory is incapable of explaining, thereby undercutting its justification by inference to the best explanation. However, in so doing they display argumentational vice: they ignore relevant work showing how complex features of organisms can be the product of natural selection; they dogmatically insist on their own preferred explanation; they abandon faith in reason for a solution that they concede transcends rational explanation; and so on. Pointing out such weaknesses in the ID theorists' reasoning is an ad hominem $\mathbf{U}_{\mathbf{U}}$ response and, as Pynes argues, entirely legitimate.

In this section we have seen four positive examples of ar-

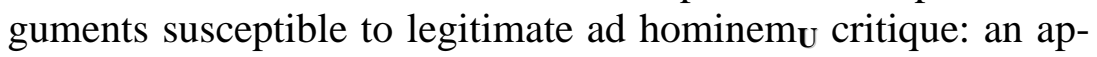
parently deductively valid argument, an inductive argument, some mathematical arguments, and an inference to the best explanation. In the next section I will show how virtue argumentation theory can handle the ad hominem fallacy in general.

(c) Andrew Aberdein. Informal Logic, Vol. 34, No. 1 (2014), pp. 77-93. 


\section{The ad hominem fallacy according to virtue theory}

In earlier work I argued that ad hominem is legitimate if and only if it is used to draw attention to argumentational vices and virtues: "For example, highlighting instances of bias, conflict of interest, or deception would be legitimate. Seeking to discredit one's opponent by focusing on his non-argumentational vices, or behaviour that is not vicious at all, would be illegitimate" (Aberdein, p. 171). Battaly adopts a similar, but more finegrained, stance towards ad hominem arguments:

three sorts of ad hominem arguments that attack the speaker's intellectual character are legitimate. These arguments attack a speaker's: (1) possession of reliabilist vices (e.g., unreliable vision); or (2) possession of fullblown responsibilist vices (e.g., dogmatism); or (3) failure to perform intellectually virtuous acts (e.g., failure to do what an open-minded person would do). [Footnote:] Ad hominems that attack a speaker's intellectual motives will not be legitimate unless those motives prevent the speaker from performing intellectually virtuous acts (Battaly, p. 367).

Battaly draws attention to a crucial aspect of virtue theory that some critics neglect: virtue theorists are not prevented from addressing acts just because they understand agent-based appraisal as conceptually prior to act-based appraisal. Thus, agent-based appraisal can turn on specific failures of virtue, as in Battaly's third sort of argument, as well as inveterate vice, as in the first two. Where my picture diverges from Battaly's is that on her account all the relevant virtues and vices are epistemic, whereas I distinguish between epistemic and argumentational vices and virtues.

On my account, "virtuous knowers are disposed to act in a way that leads to the acquisition of true beliefs, [but] virtuous arguers are disposed to spread true beliefs around" (Aberdein, p. 173). For Daniel Cohen, the distinction between the two species of virtue is more emphatic, since some of his virtues are intended to capture "cognitive but non-epistemic values" (Cohen, 2009 , p. 52). Cohen's principal argumentational virtues are willingness to engage in argumentation, willingness to listen to others, willingness to modify one's own position, and willingness to question the obvious (Cohen, 2005, p. 64). Cohen's model of virtues is ultimately Aristotelian: virtues are understood as means between pairs of vices. In previous work I extended Cohen's account, using his argumentational virtues to group to- 
gether several clusters of related intellectual virtues (Aberdein, p. 175). For example, willingness to listen to others encompasses intellectual empathy, fairmindedness, recognition of reliable authority, and recognition of salient facts, each of which may be further subdivided. Many of these argumentational virtues could also feature in a table of epistemic virtues (and some in a table of moral virtues). However, it does not follow that possessing the epistemic virtue of open-mindedness, for example, is always correlated with possession of the corresponding argumentational virtue, since they are intended to track different things. Thus an open-minded arguer might entertain challenges to otherwise well-justified belief, and end up knowing less than he did at the start of the argument (Cohen, 2009, p. 57). Such behaviour would not be epistemically virtuous, but may still be argumentationally virtuous if it successfully furthered the goals of good argument.

We are now in a position to analyse when each of the five varieties of ad hominem in the classification introduced in Section 2 is legitimate. I shall address them in reverse order. Ad hominem $_{\mathbf{U}}$ is a legitimate move when it turns on argumentational vices, whether inveterate or specific. Reducing the credence one assigns to an argument on the basis of the arguer's argumentational vice is a reasonable thing to do. That is, it exhibits argumentational virtue. Several specific virtues may be present. Perhaps the most relevant is fairness in evaluating the arguments of others, a subtype of willingness to listen to others. Willingness to engage in argumentation, which in some cases might rise to the level of intellectual courage, is also important here. (In reply, the virtuous respondent should withdraw or revise his earlier argument, thereby demonstrating virtues of his own, notably intellectual humility, an aspect of willingness to modify one's own position.) Conversely, ad hominem $\mathbf{U}$ is illegitimate when it turns on other aspects of the arguer's character. Some authors consider a much wider range of character features to be legitimate bases for ad hominem appraisal. Notably, Christopher Johnson extends the range of admissible material to encompass moral virtues and even such "non-moral character traits" as "interest in fine wine" and "experience in world travel" (Johnson, p. 262). However, his argument for so doing is that these properties are indicative of intellectual character. Hence their use in ad hominem critique would, strictly speaking, be a two-step process: (1) infer argumentational vice (or virtue) from other character traits; then (2) judge the argument on the basis of that inferred property. Since only the second step is ad hominem, this account is not really in conflict with mine. Indeed, as Johnson 
concedes, the first step would take very careful handling; hence it seems reasonable to regard anyone bypassing it, for example by jumping from a non-argumentational vice to a negative appraisal of an argument, as making an illegitimate move.

Woods's analysis of the relationship between ad hominem $_{\mathbf{U}}$ and ad hominem $\mathbf{R}$ is persuasive: many cases of ad hominem $_{\mathbf{R}}$ can best be understood as relying on an implicit ad hominem $_{\mathbf{U}}$. (There may be some cases of ad hominem $\mathbf{R}$ for which this is a poor analysis. However, it seems prima facie implausible that one could legitimately argue that an argument for which we know of no undercutter should nonetheless be rebutted on the basis of the arguer's character. So I suspect that any extraneous cases would be illegitimate, as exemplifying one or more of a variety of vices.) Hence ad hominem $\mathbf{R}_{\mathbf{R}}$ may be analysed in a similar fashion to ad hominem $\mathbf{U}$, but will be characteristically weaker since it involves an additional non-deductive step. Ad hominem $_{\mathbf{R}}$ will be legitimate when the underlying ad hominem $\mathbf{U}_{\mathbf{U}}$ turns on argumentational vices and there is no good reason to think that the conclusion could be supported independently. Thus the @ BolsoverBeast example in the previous section would also support a legitimate ad hominem $\mathbf{R}_{\mathbf{R}}$ critique, since there is no independent reason to suppose that 18 Cabinet ministers will each get a $£ 42,000$ tax cut.

Since the other varieties of ad hominem do not intrinsically address the respondent's character, we should not expect their legitimacy to be grounded in character appraisal. Nevertheless, they may still be analysed in terms of argumentational vice and virtue. Ad hominemI, or 'tu quoque', is seldom argumentationally vicious. As David Hitchcock concludes, "Fairly interpreted, real instances of the tu quoque are ... legitimate attempts to put an opponent on the spot by pointing out an apparent inconsistency between word and deed" (Hitchcock, p. 616). He stresses that this can at most provide an undercutter for the opponent's argument and, of course, that it can be misapplied if, for example, the inconsistency is only apparent. Thus, if a case of ad hominem ${ }_{I}$ is vicious, it will be for reasons that are independent of its ad hominem structure, so ad hominem ${ }_{I}$ is not associated with any characteristic vice. Ad hominems, or 'poisoning the well', is often argumentationally vicious. In many cases, seeking to silence an opponent represents a catastrophic failure of willingness to listen to others. However, it can be a legitimate move in certain circumscribed contexts, for example by restricting the right to argue in a courtroom or legislature to specific individuals. It may also be legitimate to exclude arguers guilty of extreme cases of inveterate argumentational vice, but the 
standards required would be much stricter than those for legitimate use of ad hominem $\mathbf{U}$. Lastly, ad hominem $\mathbf{C}_{\mathbf{C}}$ is never argumentationally vicious as such, although other fallacies may of course be present in specific cases.

\section{Conclusion}

We have seen that an ad hominem critique may legitimately undercut an argument, and thereby that there is scope for an agentbased account of argument appraisal to be non-fallacious. We have also seen how such an account may be used to distinguish legitimate from fallacious cases of ad hominem argument. While much remains to be done before a full virtue theory of argument may be articulated, we have seen that, properly understood, ad hominem reasoning is a favourable case study for such a theory, not an irreparable flaw.

\section{Acknowledgements}

This article was begun while I was a visiting researcher at the School of Informatics, University of Edinburgh. I am grateful to them for their hospitality and to Florida Institute of Technology for granting me sabbatical leave. An earlier version was presented at the 10th International Conference of the Ontario Society for the Study of Argumentation in Windsor, ON. I am grateful to the organizers, the audience, and particularly to Maurice Finocchiaro, whose reply to my presentation was especially helpful in preparing this article. I am also indebted to two anonymous referees for this journal.

\section{References}

Aaronson, S. (2008). Ten signs a claimed mathematical breakthrough is wrong. http://www.scottaaronson.com/blog/?p=304.

Aberdein, A. (2010). Virtue in argument. Argumentation, 24, 165-179.

Battaly, H.D. (2010). Attacking character: Ad hominem argument and virtue epistemology. Informal Logic, 30, 361-390.

Bowell, T., \& Kingsbury, J. (2013). Virtue and argument: Taking character into account. Informal Logic, 33, 22-32.

Brinton, A. (1995). The ad hominem. In H.V. Hansen \& R.C. Pinto (Eds.), Fallacies: Classical and Contemporary 
Readings (pp. 213-222). University Park, PA: Pennsylvania State University Press.

Cohen, D.H. (2005). Arguments that backfire. In D. Hitchcock \& D. Farr (Eds.), The Uses of Argument (pp. 58-65). Hamilton, ON: OSSA.

Cohen, D.H. (2009). Keeping an open mind and having a sense of proportion as virtues in argumentation. Cogency, 1, 49-64.

Copi, I.M., Cohen, C., \& Flage, D. (2007). Essentials of Logic. Upper Saddle River, NJ: Prentice Hall/Pearson, second edition.

Correia, V. (2012). The ethics of argumentation. Informal Logic, 32, 219-238.

Eemeren, F.H. van, \& Grootendorst, R. (1995). Argumentum ad hominem: A pragma-dialectical case in point. In H.V. Hansen \& R.C. Pinto (Eds.), Fallacies: Classical and Contemporary Readings, (pp. 223-228). University Park, PA: Pennsylvania State University Press.

Hinman, L.M. (1982). The case for ad hominem arguments. Australasian Journal of Philosophy, 60, 338-345.

Hitchcock, D. (2007). Why there is no argumentum ad hominem fallacy. In F.H. van Eemeren \& B. Garssen (Eds.), Proceedings of the Sixth Conference of the International Society for the Study of Argumentation, volume 1 (pp. 615620). Amsterdam: Sic Sat.

Inglis, M., \& Mejía-Ramos, J.P. (2009). The effect of authority on the persuasiveness of mathematical arguments. Cognition and Instruction, 27, 25-50.

Jason, G.J. (1984). Is there a case for ad hominem arguments? Australasian Journal of Philosophy, 62, 182-185.

Johnson, C. (2009). Reconsidering the ad hominem. Philosophy, $84,251-266$.

Locke, J. (1836). An Essay Concerning Human Understanding. London: Tegg.

Lumer, C. (2005). The epistemological approach to argumentation: A map. Informal Logic, 25, 189-212.

Macagno, F. (2013). Strategies of character attack. Argumentation, 27, 369-401.

Pollock, J.L. (1992). How to reason defeasibly. Artificial Intelligence, 57, 1-42.

Powers, L.H. (1998). Ad hominem arguments. In H.V. Hansen, C.W. Tindale \& A.V. Colman (Eds.), Argumentation and Rhetoric. Newport News, VA: Vale.

Pynes, C.A. (2012). Ad hominem arguments and intelligent design: Reply to Koperski. Zygon, 47, 289-297.

(C) Andrew Aberdein. Informal Logic, Vol. 34, No. 1 (2014), pp. 77-93. 
Salmon, M.H. (2007). Introduction to Logic and Critical Thinking. Belmont, CA: Thomson Wadsworth, fifth edition.

Siegel, H., \& Biro, J. (1997). Epistemic normativity, argumentation, and fallacies. Argumentation, 11, 277-292.

"Skinner, Denis" (@BolsoverBeast) (2013). Two thirds of the Cabinet-18 out of 29 ministers-are millionaires. Tomorrow, unlike you, they'll get a $£ 42,000$ tax cut. \#Allinittogether. March 31 2013, 10:06 a.m. Tweet.

Sorensen, R.A. (1998). Logical luck. The Philosophical Quarterly, 48, 319-334.

Walton, D.N. (1987). The ad hominem argument as an informal fallacy. Argumentation, 1, 317-331.

Walton, D.N. (2006). Poisoning the well. Argumentation, 20, 273-307.

Woods, J. (2007). Lightening up on the ad hominem. Informal Logic, 27, 109-134. 